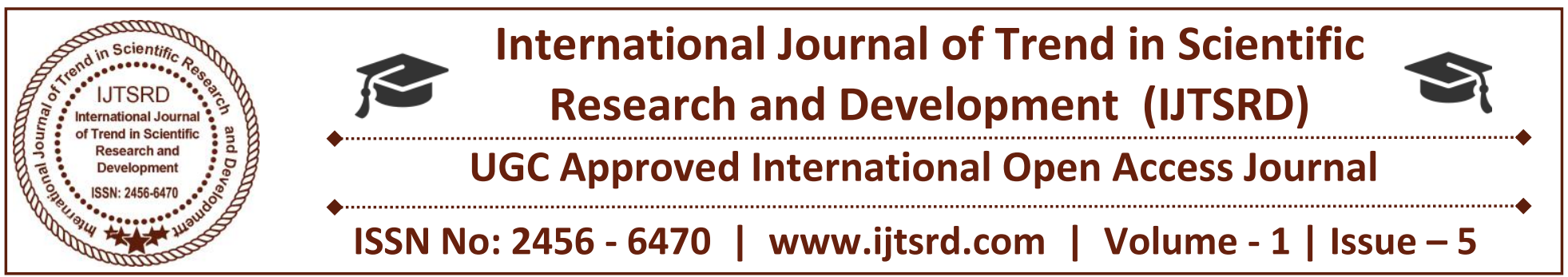

\title{
Fe75-xCoxCu1Nb3Si15B6 alloy with Rapid Stress Annealing
}

\author{
Shailendra Singh Khinchi \\ Department of Applied Physics \\ Institute of Engineering and Technology \\ Devi Ahilya University, Indore, India
}

\section{ABSTRACT}

This article reports the effect of stress annealing treatment on the structural and magnetic properties of nanocrystalline $\mathrm{Fe}_{75-\mathrm{x}} \mathrm{Co}_{\mathrm{x}} \mathrm{Cu}_{1} \mathrm{Nb}_{3} \mathrm{Si}_{15} \mathrm{~B}_{6} \& \mathrm{Co}_{21} \mathrm{Fe}_{64-}$ ${ }_{x} \mathrm{Nb}_{\mathrm{x}} \mathrm{B}_{15}$ alloys. Information obtained from magnetic measurements, X-ray diffraction measurements and Mössbauer spectroscopy reveal that for $\mathrm{Fe}_{75}$ ${ }_{x} \mathrm{Co}_{\mathrm{x}} \mathrm{Cu}_{1} \mathrm{Nb}_{3} \mathrm{Si}_{15} \mathrm{~B}_{6}(\mathrm{x}=0,2,5)$ alloys the volume fraction of the $\mathrm{Fe}-\mathrm{Co}$ nanograins and their grain diameter ranges between 56 to $80 \%$ and 10 to $18 \mathrm{~nm}$ respectively. Annealing treatment at higher temperature also resulted in appearance of $\mathrm{Fe}_{3} \mathrm{Si}$ nanocrystals along with magnetically hard $\mathrm{Fe}_{3} \mathrm{~B}$, $\mathrm{Fe}_{23} \mathrm{~B}$ type phases which are responsible for higher coercive field values. Presence of cobalt and applied stress during annealing has considerable effect on relative permeability and stress induced anisotropy, which is and perpendicular to the ribbon axis. Mössbauer spectroscopy analysis also suggests changes in spin texture.

\section{INTRODUCTION}

Nanocrystalline FINEMET-type alloys [1] exhibiting both reduced squareness ratio, losses and linear permeability are especially attractive for applications. Optimized alloy composition and suitable thermal treatments will have effect on the magnetic properties of the nanocrystalline structure, needed for various applications and Co is found to be effective for this purpose [2]. Rapid stress annealing is a fast and convenient way for the production of wound annealed cores displaying different permeability values, high induced anisotropy [3] and improved ductility, highly desirable for applications. In this section we report the influence of rapid stress annealing on structural and magnetic properties of nanocrystalline $\mathrm{Fe}_{75}$ ${ }_{\mathrm{x}} \mathrm{Co}_{\mathrm{x}} \mathrm{Cu}_{1} \mathrm{Nb}_{3} \mathrm{Si}_{15} \mathrm{~B}_{6}(\mathrm{x}=0,2,5)$ alloys using magnetic measurements X-ray diffraction (XRD) and Mössbauer spectroscopy.

\section{EXPERIMENTAL DETAILS}

Ribbons having composition $\mathrm{Fe}_{75-\mathrm{x}} \mathrm{Co}_{\mathrm{x}} \mathrm{Cu}_{1} \mathrm{Nb}_{3} \mathrm{Si}_{15} \mathrm{~B}_{6}$ $(\mathrm{x}=0,2,5)(20 \mu \mathrm{m}$ thick and $10 \mathrm{~mm}$ wide $)$ were prepared using a planar flow casting technique. Samples were annealed with / without stress, between 500 to $800{ }^{0} \mathrm{C}$ for 10 seconds, and the applied stress ( $\sigma$ ) during annealing was between 0 to $280 \mathrm{MPa}$. Measured $\mathrm{Cu}-\mathrm{K}_{\alpha}$ XRD patterns were analyzed by fitting a crystalline and amorphous component using pseudo-voigt line profile to obtain the Schereer's grain diameter $(D)$, crystalline volumetric fraction $\left(V_{x}\right)$. For amorphous phase, first near-neighbor distance between atoms $\left(X_{m}\right)$ was obtained using: $X_{m}$ $=1.227 \lambda / 2 \sin \theta$. Hysteresis loops were measured using a computerized quasi-static hysteresis loop tracer. Induced anisotropy constant $K_{\sigma}$, is derived from hysteresis curves. Permeability was measured using impedance meter. Transmission Mössbauer spectra were recorded at room temperature in a constant acceleration mode, using ${ }^{57} \mathrm{Co}: \mathrm{Rh}$ source; fitted with overlapping of amorphous and crystalline components using NORMOS program [4].

\section{RESULTS AND DISCUSSIONS}

Representative XRD patterns (for specimens with $\mathrm{x}=$ 0 and $\sigma=0$ ) were obtained after annealing at 660, 700 and $750{ }^{0} \mathrm{C}$ reveal that the $V_{x}$ ranges between 56 to 80 $\%$ whereas their average grain diameter ranges 
between 10 to $18 \mathrm{~nm}$. XRD confirms the formation of $\mathrm{Fe}_{3} \mathrm{Si}$ nanocrystals up to annealing at $700{ }^{\circ} \mathrm{C}$, and annealing at $750{ }^{0} \mathrm{C}$ leads to the formation of magnetically hard boride phases $\left(\mathrm{Fe}_{3} \mathrm{~B}, \mathrm{Fe}_{23} \mathrm{~B}\right)$. Annealing (no stress) temperature dependence of coercive field ' $H_{c}$ ' is shown in Figure 1. Annealing up to $700{ }^{0} \mathrm{C}$ the studied alloys exhibit soft magnetic behavior. Annealing temperatures higher than $700{ }^{0} \mathrm{C}$, a sharp increase of the $H_{c}$ in all the studied alloys is ascribed to the appearance ofhard magnetic Fe-B phase as confirmed by XRD measurements.

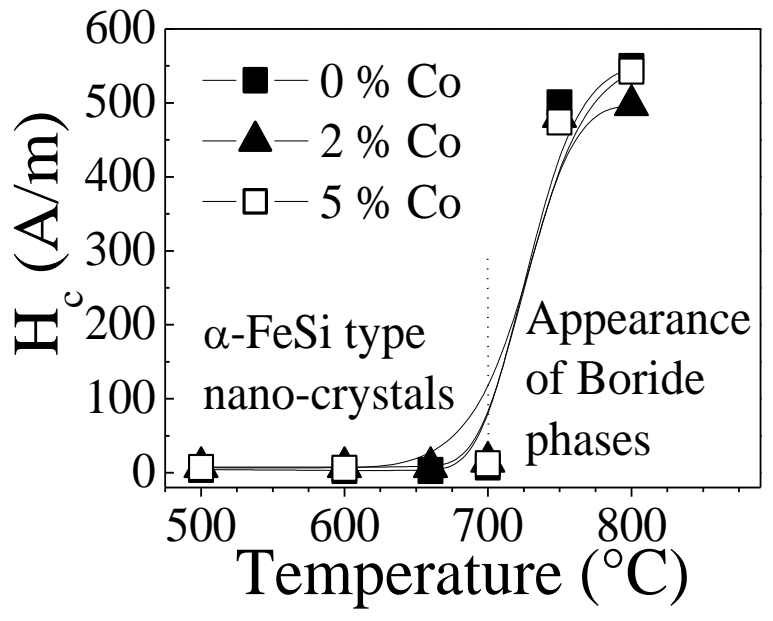

Figure 1: Annealing temperature dependence of coercive field for $\mathrm{Fe}_{75-\mathrm{x}} \mathrm{Co}_{\mathrm{x}} \mathrm{Cu}_{1} \mathrm{Nb}_{3} \mathrm{Si}_{15} \mathrm{~B}_{6}$ $(x=0,2,5)$ alloys with varying Co content. Line connecting points are guide to the eye.

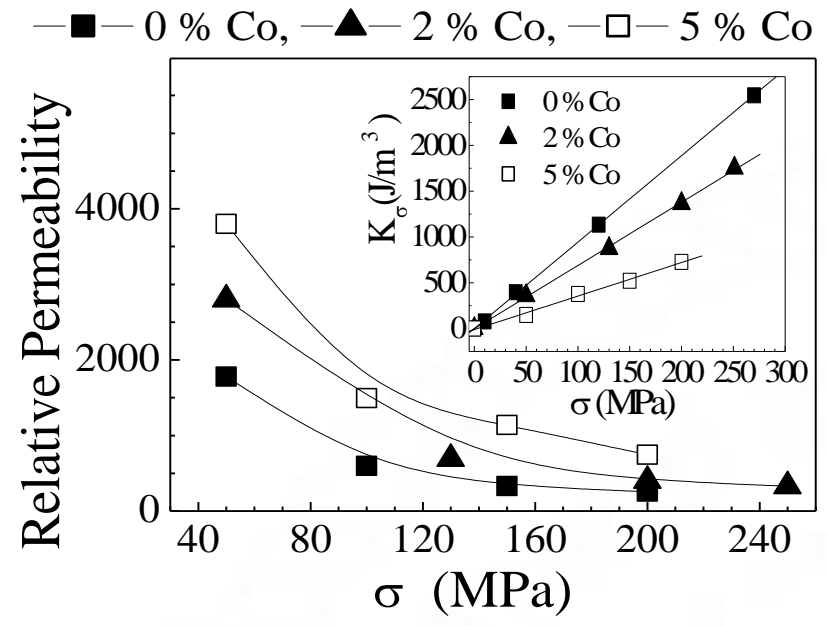

Figure 2: Relative permeability variation after rapid stress annealing at $655{ }^{\circ} \mathrm{C} / 10$ sec., with stress for the studied specimens. Solid lines are guide to the eye. Inset: Variation of Induced anisotropy with stress. Solid lines are linear fit to the experimental data.

Figure 2 depicts the variation of relative permeability after rapid stress annealing as a function of stress and inset of fig. 2 shows the variation of induced anisotropy as a function of applied stress. Perusal of figure 2 shows that, relative permeability monotonically decreases with increase of the stress during annealing treatment.

Mössbauer measurements on as-cast samples with Co $=0,2,5$ show that $\mathrm{I}_{2,3}$ (intensity of $2^{\text {nd }}$ and $5^{\text {th }}$ lines relative to innermost lines of the Mössbauer spectrum) is a measure of spin texture in the specimen, ranges between 2.15 to 2.23 is close to random distribution of spins; $\mathrm{B}_{\mathrm{hf}}$ (average hyperfine field) ranges between 28.72 to 29.25 Tesla and $\Delta B_{\text {hf }}$ / $\mathrm{B}_{\mathrm{hf}}$ - (fractional width of the hyperfine field distribution, $\Delta \mathrm{B}_{\mathrm{hf}}$-width of field distribution) which is a measure of disorder in the specimen ranges between 0.261 to 0.265 , revealing similar disorder. 


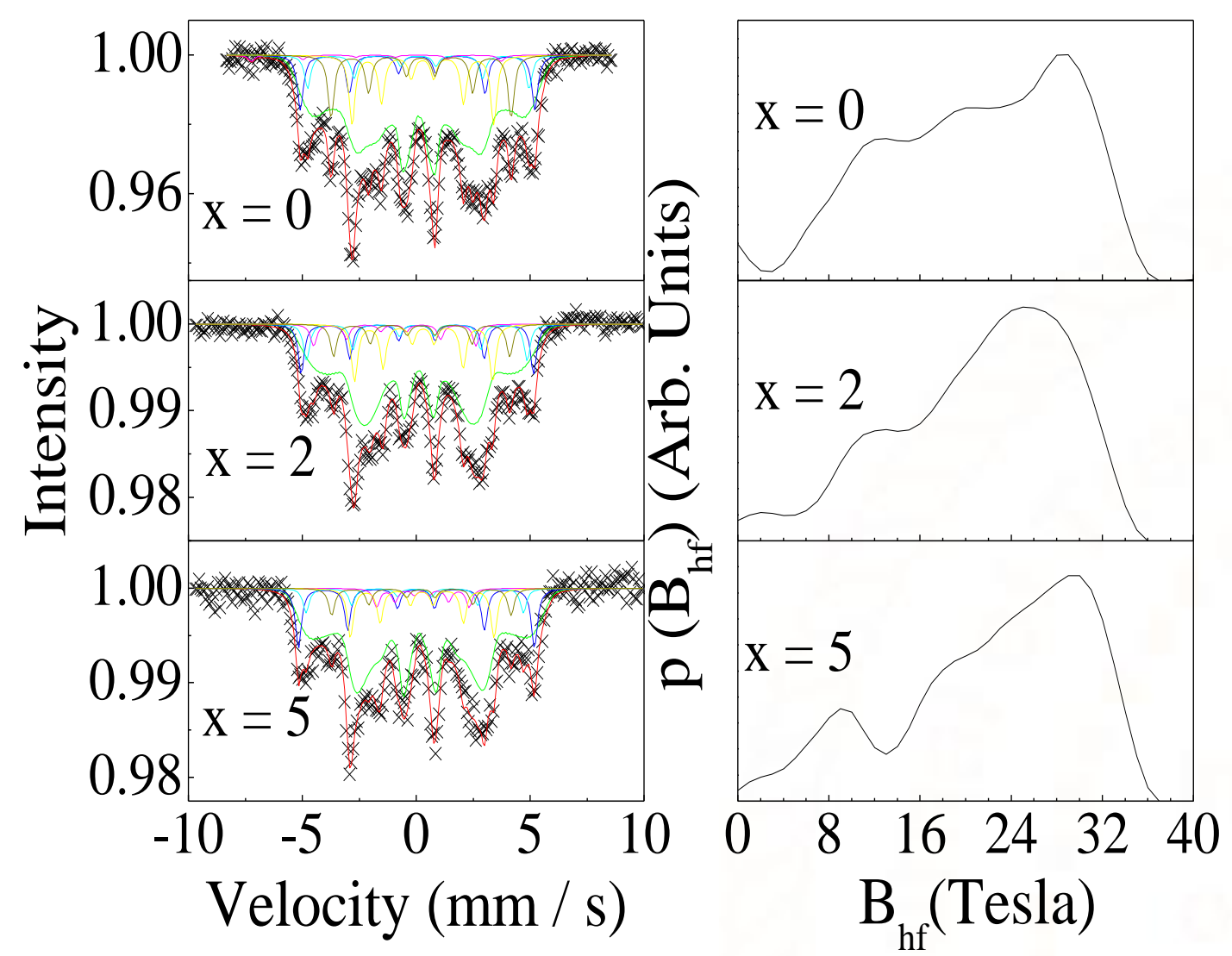

Figure 3: Representative Mössbauer spectra and the corresponding hyperfine field distribution (for residual amorphous phase) for rapid annealed (no stress) samples, at $600{ }^{\circ} \mathrm{C} / 10 \mathrm{sec}$. with varying Co-content.

Figure 3 depicts the Representative Mössbauer spectra and the corresponding hyperfine field distribution for rapid annealed (no stress) samples, at $600{ }^{\circ} \mathrm{C} / 10 \mathrm{sec}$. with varying Co-content. Perusal of figure 3 shows that in hyperfine field distribution a low field hump 9 Tesla suggests the presence of $\mathrm{Nb}$ near-neighbors to Fe [5]. $\mathrm{I}_{2,3}$, area of crystalline phase, and

$\Delta \mathrm{B}_{\mathrm{hf}} / \mathrm{B}_{\mathrm{hf}}$ for the samples with $\mathrm{x}=0,2$ and 5 respectively ranges between 1.67 to $2.91 ; 63.4$ to 66.9 and 0.361 to 385 suggesting that variation of $\mathrm{Co}$ content in the alloy affects the crystalline fraction, spin texture and disorder. Relative area (RA) also shows changes with co-content in the alloy. Table 1 depicts the hyperfine parameters of annealed at $600^{\circ} \mathrm{C}$ for $10 \mathrm{sec}$. at $100 \mathrm{MPa}$ stress. Perusal of table 1 shows that the stress annealing affects the disorder in the residual amorphous matrix and area of crystalline phase and spin texture. 
Table 1: Hyperfine parameters of the samples annealed at $600{ }^{\circ} \mathrm{C} / 10$ sec. at $100 \mathrm{MPa}$ stress.

\begin{tabular}{|c|c|c|c|c|c|c|}
\hline \multirow{2}{*}{$\begin{array}{c}\text { Co } \\
\text { content }\end{array}$} & \multicolumn{2}{|c|}{ Area } & \multirow{2}{*}{$\begin{array}{l}B_{h f}(\mathrm{~T}) \\
( \pm 0.41)\end{array}$} & \multirow{2}{*}{$\begin{array}{c}\Delta B_{h f}(\mathrm{~T}) \\
( \pm 0.4)\end{array}$} & \multirow[t]{2}{*}{$\Delta B_{h f} / B_{h f}$} & \multirow{2}{*}{$\begin{array}{c}I_{2,3} \\
( \pm 0.09)\end{array}$} \\
\hline & A (\%) & RA (\%) & & & & \\
\hline $\mathbf{0}$ & $\begin{array}{l}66.81 \\
33.19\end{array}$ & $\begin{array}{l}20.43 \\
23.27 \\
10.72 \\
16.34 \\
29.24\end{array}$ & $\begin{array}{l}22.32 \\
30.47 \\
32.14 \\
16.24 \\
16.47 \\
19.26\end{array}$ & 7.21 & 0.323 & 2.59 \\
\hline 2 & $\begin{array}{l}71.41 \\
28.59\end{array}$ & $\begin{array}{l}39.66 \\
35.34 \\
04.80 \\
11.03 \\
09.17\end{array}$ & $\begin{array}{c}22.97 \\
31.54 \\
19.5 \\
15.43 \\
24.69 \\
19.48\end{array}$ & 7.46 & 0.325 & 1.96 \\
\hline 5 & $\begin{array}{l}72.33 \\
27.67\end{array}$ & $\begin{array}{l}34.79 \\
05.05 \\
06.76 \\
27.46 \\
25.95\end{array}$ & $\begin{array}{l}22.17 \\
31.83 \\
29.86 \\
16.18 \\
19.52 \\
24.63\end{array}$ & 8.43 & 0.380 & 1.51 \\
\hline
\end{tabular}

\section{CONCLUSIONS}

We have studied the influence of rapid stress annealing on structural and magnetic properties of nanocrystalline $\mathrm{Fe}_{75-\mathrm{x}} \mathrm{Co}_{\mathrm{x}} \mathrm{Cu}_{1} \mathrm{Nb}_{3} \mathrm{Si}_{15} \mathrm{~B}_{6}(\mathrm{x}=0,2,5)$ alloys. XRD patterns for the specimens with $\mathrm{x}=0$ reveal that the volume fraction of the nanograins and their grain diameter ranges between 56 to $80 \%$ and 10 to $18 \mathrm{~nm}$ respectively. XRD confirms that annealing below $700{ }^{0} \mathrm{C}$ leads to the formation of $\mathrm{Fe}_{3} \mathrm{Si}$ type nanocrystals and above $700{ }^{0} \mathrm{C}$, magnetically hard $\mathrm{Fe}_{3} \mathrm{~B}, \mathrm{Fe}_{23} \mathrm{~B}$ phases also appear, leading a sharp increase of the coercive field. Both applied stress (during rapid stress annealing) and Co content in the parent alloy has considerable effect on relative permeability and stress induced anisotropy, which is and perpendicular to the ribbon axis. Mössbauer measurements suggest changes in spin texture after annealing with/without stress.

\section{REFERENCES}

1) Y. Yoshizawa, S. Oguma, K. Yamaguchi, J. Appl. Phys. 64 (1988) 6044.
2) Zs. Gercsi, S. N. Kane, J. M. Greneche, L. K. Varga and F. Mazaleyrat Phys. Stat. Sol. (C) 1 (2004) 3607; C. Gomez-Polo, J. I. PérezLandazabal, V. Recarte, J. Campo, P. Marín, M. López, A. Hernando and M. Vázquez, Phys. Rev. B66, (2002) 12401.

3) F. Alves, J. Magn. Magn. Mat. 226-230 (2001) 1490; F. Alves, F. Simon, S. N. Kane, F. Mazaleyrat, T. Waeckerle, T. Save and A. Gupta, J. Magn. Magn. Mater. 294 (2005) e141.R. A. Brand, Nucl. Instr. Meth. B 28 (1987) 398.

4) A. Gupta, S. N. Kane, N. Bhagat and T. Kulik, J. Magn. Magn. Mater. 254-255 (2003) 492

5) Kharate G. K., Patil V. H., "Color Image Compression Based On Wavelet Packet Best Tree," IJCSI International Journal of Computer Science Issues, Vol. 7, Issue 2, No 3, March 2010.

6) Singh, Sanjeev Chopra, Harmanpreet Kaur, Amandeep Kaur Image Compression Using Wavelet and Wavelet Packet Transformation IJCST Vol. 1, Issue 1, September 2010. 